\title{
Programas de promoção da saúde do idoso: uma revisão da literatura científica no período de 1990 a 2002
}

\author{
Health promotion programs for the elderly: \\ a review of cientific literature from 1990 to 2002
}

Mônica de Assis 1

Zulmira M. A. Hartz 2

Victor Vincent Valla 2

\footnotetext{
1 Universidade Aberta da Terceira Idade, UERJ. Rua São Francisco Xavier 525 , bloco F, 10 o andar, Maracanã, 20550-011, Rio de Janeiro RJ. www.unati.uerj.br 2 Escola Nacional de Saúde Pública, Fiocruz.
}

Abstract This article presents a panel about the experiences on evaluation of health promotion programs for the elderly starting from a systematic literature review. A bibliography search was performed on databases, on websites and specialized journals published between 1990 and 2002. Only programs with multi-theme focus that contemplated educative and/or preventive activities were considered. The data revealed a multidimensional field regarding theoretical and methodological trends and research strategies. In international cases, a study design prevails that is quasi-experimental. In Brazil, reports of experiences are more common. The most important dimensions evaluated on these works are the receptivity among the elderly, the improvement of psycological and social indicators, the adherence to behavioral recommendations and the educative process. The results indicate good adhesion among the elderly and discrepancy of effects on the quantitative measurement of indicators. The qualitative results point to ways of understanding these processes. One can conclude that the evaluation on health promotion programs for the elderly is still weakly developed in Brazil and that the research of the synthesis of the evaluated programs can be a parameter for the development of experiences in our context.

Key words Health promotion elderly, Programs evaluation, Health education
Resumo $O$ artigo mostra as experiências de avaliação em promoção da saúde do idoso a partir da revisão de programas na área. Fez-se busca bibliográfica em bases de dados, sites e periódicos especializados, no período 1990-2002. O critério de inclusão foi ser programa com foco multitemático com atividades educativas elou preventivas. Os estudos revisados revelam um campo multifacetado quanto às tendências teórico-metodológicas e às estratégias de pesquisa. Na experiência internacional predomina o estudo quase-experimental, enquanto no Brasil são comuns os relatos de experiências. As principais dimensões avaliadas nos estudos são a receptividade dos idosos, a melhoria de indicadores psicossociais, a aderência a recomendações comportamentais e o processo educativo. Nos resultados destacam-se a boa receptividade dos idosos e certa discrepância de efeitos na aferição quantitativa de indicadores. Os estudos qualitativos apontam caminhos para apreensão dos processos. Conclui-se que a avaliação em promoção da saúde do idoso é pouco desenvolvida no Brasil e a pesquisa de síntese dos programas pode ser parâmetro para o desenvolvimento das experiências em nosso contexto.

Palavras-clave Promoção da saúde do idoso, Avaliação de programas, Educação em saúde 
Os programas devem oferecer um espaço em que a reformulação de padrões tradicionais de envelhecimento possa ser uma experiência coletiva e no qual participar deles ativamente signifique viver intensamente uma nova etapa da vida, um momento próprio para exploração da identidade e de novas formas de auto-expressão (Maria Auxiliadora C. Ferrari, 1999).

\section{Introdução}

Programas de promoção da saúde do idoso são cada vez mais requeridos em face das demandas crescentes do envelhecimento populacional. A promoção da saúde é um tema em evidência na atualidade e que traz desafios para a ampliação das práticas no sentido de ressaltar os componentes socioeconômicos e culturais da saúde e a necessidade de políticas públicas e da participação social no processo de sua conquista (Buss, 2003; Rootman, 2001). Do ponto de vista gerontológico, o tema converge com a promoção do envelhecimento ativo, caracterizado pela experiência positiva de longevidade com preservação de capacidades e do potencial de desenvolvimento do indivíduo, para o que a garantia de condições de vida e de políticas sociais são uma prerrogativa (WHO, 2002).

A incorporação da visão de promoção da saúde nos programas para idosos supõe uma abordagem crítica da prevenção e da educação em saúde e pode ser vista como um processo social em curso, complexo, que vem sendo estimulado em nível internacional por fóruns e documentos institucionais desde meados da década de 1980.

$\mathrm{O}$ estudo apresentado neste artigo integrou o processo de avaliação do projeto de promoção da saúde desenvolvido no Núcleo de Atenção ao Idoso (NAI), um dos ambulatórios da Universidade Aberta de Terceira Idade - UnATI/UERJ (Assis, 2004). O projeto é uma iniciativa interdisciplinar que busca articular práticas educativas com idosos a ações preventivas e assistenciais, orientadas por princípios da Educação Popular em Saúde (Vasconcelos, 2001; Valla, 2000). Experiências próximas a esta vêm sendo implantadas no Brasil e impõem a necessidade de avaliação como estratégica para a expansão dos programas para idosos no país.

O objetivo do texto é apresentar um painel de como a avaliação de programas de promoção da saúde do idoso aparece na literatura contemporânea e possibilitar parâmetros teó- rico-metodológicos para a análise de experiências similares.

\section{Metodologia}

O conjunto de estudos analisados foi identificado através de pesquisa bibliográfica sistemática, cuja principal fonte foram as bases de dados Medline e Lilacs, no período 1990-2002, a partir das expressões health promotion elderly program e programa de promoção da saúde do idoso. Também foram revisados periódicos de saúde pública, envelhecimento e educação em saúde, disponíveis em bibliotecas especializadas (UnATI/UERJ, ENSP, USP, IMS/UERJ), além de sites e livros sobre o assunto.

$\mathrm{Na}$ busca bibliográfica geral nas bases de dados observou-se que a maioria dos estudos enfoca pontualmente uma temática, seja o controle de patologias (osteoporose, câncer, doenças cardiovasculares, depressão, demências, dentre outras), sejam os fatores de risco ou ações específicas, como quedas, saúde oral, imunização, alimentação e, destacadamente, atividade física.

Por ser um campo extremamente diversificado, optou-se pela inclusão apenas de programas com foco multitemático e características próximas à experiência realizada no NAI/UnATI (ação educativa articulada à avaliação individual com fins preventivos e assistenciais). Para maior homogeneidade dos programas analisados, não foram incluídas avaliações globais sobre as experiências das Universidades de Terceira Idade, apesar de se reconhecerem estes espaços como promotores de saúde por excelência (Neri \& Cachioni, 1999, e Frutuoso, 1999). O quadro 1 mostra os critérios definidos no processo de busca e ilustra as temáticas recorrentes na literatura. Como se observa, outros eixos de interesse foram incluídos, mas a análise tomará como alvo os programas, delimitados da maneira apontada.

De modo geral, constata-se a disparidade entre a literatura internacional e a latino-americana em termos de volume dos estudos e também quanto à sua densidade (quadros $2 \mathrm{e}$ 3). No que tange ao Brasil, tal fato mostra, dentre outros aspectos, a trajetória recente da abordagem do envelhecimento, refletindo a ainda pequena produção sobre avaliação de programas nesta área.

Pela razão exposta, os critérios para inclusão de estudos nacionais foram flexibilizados 


\section{Quadro 1}

Critérios de inclusão e exclusão na revisão sistemática da literatura sobre programas de promoção da saúde do idoso.

Inclusão

\section{Exclusão}

- Foco na população idosa

- Discussão conceitual e/ou institucional sobre promoção da saúde

- Programas relacionados ao controle de doenças, ações ou fatores de risco específicos (osteoporose, câncer, imunizações, saúde oral, fumo, quedas, doença cardiovascular, depressão,

- Programas de promoção da saúde com foco multitemático e características próximas ao PPS do NAI/UnATI

- Aspectos políticos na implantação de programas

- Avaliação de autocuidado / problematização sobre prevenção, crenças e comportamento em saúde

- Envelhecimento saudável, apoio social e saúde do idoso

- Avaliação multidimensional / estudos epidemiológicos sobre qualidade de vida do idoso

- Aspectos sobre práticas profissionais específicas em promoção da saúde

- Comunicação / educação em saúde / aconselhamento saúde mental, atividade física, alimentação, dentre outras)

- Programas dirigidos a subgrupos específicos dos idosos (asilados, área rural, grupos étnicos, etc.) => exceção para mulher e idosos de baixa renda

- Programas sem foco na população idosa

- Estudos sobre efeitos da atividade física (pesquisa básica, desporto, etc.)

- Estudos sobre questões nutricionais específicas

- Comentário de caráter geral (1 ou 2 pág.)

- Referência sem resumo e/ou de interesse improvável

- Idioma não acessível (outros além do inglês, espanhol e francês)

Quadro 2

Revisão bibliográfica sobre Programa de Promoção da Saúde do Idoso, nas bases de dados Medline e Lilacs, 1990-2002.

\begin{tabular}{|c|c|c|c|c|}
\hline \multirow[t]{2}{*}{ Palavras-chave } & \multicolumn{4}{|c|}{ № de estudos } \\
\hline & $\begin{array}{c}\text { Relacionados } \\
\text { na Base }\end{array}$ & Pré-selecionados & $\begin{array}{l}\text { Eliminados } \\
\text { pelo resumo }\end{array}$ & $\begin{array}{c}\text { Revisão pelos critérios } \\
\text { gerais de inclusão }\end{array}$ \\
\hline Medline & & & & \\
\hline $\begin{array}{l}\text { Health Promotion } \\
\text { Elderly Program }\end{array}$ & 2021 & 120 & 5 & 115 \\
\hline Lilacs & & & & \\
\hline Programa Promoção Saúde Idoso & 7 & 1 & 1 & - \\
\hline Educação em Saúde do Idoso* & 45 & 9 & 5 & 4 \\
\hline Total & 52 & 10 & 6 & 4 \\
\hline
\end{tabular}

* A busca através dessa expressão ocorreu devido ao número pequeno de referências obtido com a primeira. 
Quadro 3

Revisão bibliográfica sobre Programa de Promoção da Saúde do Idoso, nas bases de dados Medline e Lilacs, segundo foco temático, 1990-2002.

\begin{tabular}{|c|c|c|c|}
\hline \multirow[t]{2}{*}{ Foco temático } & \multicolumn{3}{|c|}{ № estudos } \\
\hline & Medline & Lilacs & Total \\
\hline - Discussão conceitual e/ou institucional & 25 & 0 & 25 \\
\hline $\begin{array}{l}\text { - Programas de promoção da saúde com foco multitemático } \\
\text { e características próximas ao PPS do NAI/UnATI }\end{array}$ & 23 & 3 & 26 \\
\hline - Aspectos políticos na implantação de programas de promoção da saúde & 2 & 0 & 2 \\
\hline $\begin{array}{l}\text { - Avaliação de autocuidado / problematização sobre crenças } \\
\text { e comportamento em saúde }\end{array}$ & 25 & 1 & 26 \\
\hline - Apoio social e saúde do idoso & 1 & 0 & 1 \\
\hline $\begin{array}{l}\text { - Avaliação Multidimensional / estudos epidemiológicos gerais } \\
\text { sobre qualidade de vida do idoso }\end{array}$ & 6 & 0 & 6 \\
\hline - Aspectos sobre práticas profissionais específicas em promoção da saúde & 4 & 0 & 4 \\
\hline - Comunicação / Educação em Saúde / Aconselhamento & 10 & 0 & 10 \\
\hline - Não classificada por falta de resumo & 19 & 0 & 19 \\
\hline Total & 115 & 4 & 119 \\
\hline
\end{tabular}

para garantir o acesso a um conjunto mínimo de experiências, semelhantes a outras em curso no país mas não avaliadas e/ou divulgadas via publicação. Os estudos não totalmente enquadrados nos critérios são os de Lopes et al. (1999) e Portella (1999) por se dirigirem também à população adulta, e o de Rodrigues et al. (1999), por motivo similar dado o corte etário de 44 anos. Outra característica da produção brasileira, como já sugerido, é que boa parte não se refere a estudos propriamente de avaliação, mas são relatos de experiência que contemplam aspectos avaliativos.

A busca em fontes diversas é apresentada no quadro 4 e obedece a períodos de tempo variados conforme a disponibilidade dos acervos. Aqui é apresentado especificamente a busca de programas de acordo com o critério proposto.

Dos 35 programas identificados foram efetivamente acessados 20 estudos (11 internacionais e 9 brasileiros), em função dos limites encontrados nos meios de comutação bibliográfica.

A sistematização adiante apresentada destacará a experiência internacional e a brasileira e terá como base os seguintes eixos de análise: as características institucionais dos programas e da população envolvida, a forma como estruturam e organizam a ação educativa, o desenho metodológico da avaliação e os principais resultados, limites e recomendações. A revisão sistemática pretendida não abrange a análise das te- orias dos programas, tal como proposta na metodologia de sintese realista de Pawson (2002), porém busca igualmente tirar lições não apenas dos sucessos dos programas mas de seus mecanismos e obstáculos. Assume-se a importância da pesquisa de síntese para o desenvolvimento de políticas, especialmente para o diálogo das iniciativas em curso com a construção contemporânea do referencial da promoção da saúde.

\section{Resultados}

\section{Características institucionais e perfil da população envolvida}

A maioria das experiências no Brasil é desenvolvida em serviços públicos de saúde, vinculada à assistência regular. Dentre as demais, duas são realizadas em instituições de ensino via extensão universitária, uma pela Sociedade Brasileira de Geriatria e Gerontologia e uma outra sem vínculo institucional. Nos estudos internacionais observa-se algo semelhante, com o diferencial de que em dois programas as ações são oferecidas de modo subordinado à pesquisa e de que predominantemente há financiamento específico por parte de agências públicas ou privadas.

O padrão internacional e brasileiro também assemelha-se quanto às áreas profissionais 
Quadro 4

Revisão bibliográfica sobre Programa de Promoção da Saúde do Idoso em periódicos selecionados e outras fontes.

\begin{tabular}{|c|c|c|c|}
\hline & Editor ou local & Período & № estudos \\
\hline \multicolumn{4}{|l|}{$\begin{array}{l}\text { Periódicos das áreas de saúde pública, } \\
\text { envelhecimento e outras }\end{array}$} \\
\hline Cadernos de Saúde Pública & ENSP & $1992-2002$ & 0 \\
\hline Saúde em Debate & CEBES & $1992-2002$ & 0 \\
\hline Ciência e Saúde Coletiva & Abrasco & $1996-2002$ & 0 \\
\hline Physis & IMS/UERJ & $1991-2001$ & 0 \\
\hline Revista de Saúde Pública & USP/SP & $1992-2002$ & 0 \\
\hline Revista Panamericana de Salud Pública & OPAS & $1992-2002$ & 0 \\
\hline Textos sobre Envelhecimento & UnATI/UERJ & $1998-2002$ & $1^{\star}$ \\
\hline A Terceira Idade & SESC/SP & $1988-2001$ & 0 \\
\hline Arquivos de Geriatria e Gerontologia & SBGG/RJ & $1996-2000$ & 0 \\
\hline Gerontologia & SBGG/SP & $1993-2000$ & 3 \\
\hline Bulletin on Ageing & Ong Int. & $1991-2000$ & 0 \\
\hline Ageing and Society & Cambridge & 1995-1999 & 0 \\
\hline Research on Aging & Londres & $1992-2002$ & 1 \\
\hline The Gerontologist & EUA & $1990-2002$ & 1 \\
\hline The Journals of Gerontology & ONU & 1994-1998 & 0 \\
\hline Revista Brasileira de Enfermagem & ABENF & $1992-2002$ & 1 \\
\hline \multicolumn{4}{|l|}{ Outras fontes } \\
\hline Livros/Capítulos & - & - & 1 \\
\hline Sites da área & - & - & 1 \\
\hline Teses da Fiocruz & Fiocruz / RJ & $1990-2002$ & 1 \\
\hline Banco de Teses Capes & - & $1996-2002$ & 0 \\
\hline Total & & & 9 \\
\hline
\end{tabular}

* Artigo não incluído na revisão por ser referente à experiência do projeto de promoção da saúde do NAI/UnATI.

envolvidas nas ações com os idosos. Em metade dos estudos a equipe é composta de pelo menos três áreas diferentes, com predomínio das clássicas profissões ligadas à saúde mas com presença de variados campos disciplinares. É expressivo também o número de programas com apenas uma área envolvida, comumente a enfermagem, presente em seis dos sete estudos nesta condição. Três programas não mencionam a composição da equipe.

A dinâmica do trabalho em equipe multidisciplinar não é clara na maior parte dos trabalhos. É possível observar que muitas vezes tratase da participação estanque de profissionais de áreas diversas sem maior integração. Poucas experiências referem espaços de encontro e construção conjunta do trabalho pela equipe.

Quanto ao formato dos programas, metade se estrutura para oferecer atividades educativas em nível coletivo e dois se baseiam somente em ações preventivas individuais de screenings e aconselhamento. A combinação das duas estra- tégias ocorre em quatro experiências internacionais, enquanto no Brasil quatro programas se desenvolvem na própria rotina de assistência à saúde.

Nos estudos internacionais, a maioria da população idosa envolvida encontra-se relativamente bem, dispõe de seguro saúde, possui nível educacional alto e status de saúde e renda acima da média. Apenas dois são realizados com idosos pobres, enquanto dois têm níveis socioeconômicos diversificados. No Brasil, a maioria dos trabalhos não apresenta dados da população participante ou limita-se a variáveis como sexo, idade, ou área geográfica. Dos três estudos que especificam um pouco mais, um é realizado com população idosa com indicadores mais favoráveis que a média nacional, enquanto dois são com usuários do SUS, em bairros periféricos, com grande índice de analfabetismo e baixa escolaridade. As mulheres são a maioria no conjunto global dos programas e o estado conjugal é variado, com predomínio de viúvas. 


\section{Estruturação e bases teóricas das ações}

De modo geral, os objetivos dos programas convergem no horizonte de melhoria da saúde e qualidade de vida do idoso, com acento ora em mudanças comportamentais / práticas de saúde ora em dimensões subjetivas e sociais do bem-estar ou em ambas combinadas.

As ações educativas de caráter coletivo são organizadas desde pequenos grupos até eventos de maior porte e de forma similar nas experiências nacionais e internacionais. Analisando o conjunto de programas, pode-se identificar os seguintes formatos de ação educativa igualmente recorrentes: grupos de até 20 pessoas, fechados, com periodicidade definida; grupos ou sessões de educação em saúde, abertos, continuados; programas de workshops ou palestras, fechados, com periodicidade definida. Em uma única experiência a ação organiza-se como evento único com diversas atividades educativas. Em dois programas internacionais há referência a alguma atividade prática além das sessões educativas, como exercícios, sessões de administração do estresse e lanches, enquanto um estudo nacional refere o grupo da caminhada.

A duração dos grupos fechados, com periodicidade definida, é de 4, 8 e 26 sessões nos programas internacionais e de 4 e 16 sessões nos programas brasileiros. A programação temática abrange um amplo leque de questões relaciona- das à saúde no processo de envelhecimento, com ênfase em dimensões do autocuidado. Temas que vão além dos classicamente relacionados à saúde são também mencionados em algumas experiências. Em sete estudos (cinco nacionais e dois internacionais), a programação é definida em conjunto com os participantes a partir do primeiro encontro. Nos demais não há informação clara sobre este aspecto.

Os referenciais teóricos apontados pelos autores são diversos e é comum a combinação de enfoques em um mesmo programa. O quadro 5 mostra sua recorrência no conjunto estudado.

Quando não explicitado um modelo ou teoria subjacente, optou-se por destacar os princípios ou referências conceituais que balizam as ações. Isso ocorre em quatro experiências brasileiras e igualmente em quatro internacionais. No Brasil, são referidas a importância do grupo para os idosos, os conceitos da OPAS e OMS sobre o envelhecimento, a política nacional do idoso e concepções críticas sobre autocuidado e sobre a consulta de enfermagem. Nos programas internacionais são apontadas a base epidemiológica da prevenção com idosos e o debate acerca da efetividade dos programas e dos preditores da participação nos mesmos.

Como mostrou o quadro 5, neste aspecto há diferenças entre o padrão internacional e o brasileiro. A referência à pedagogia de Paulo Freire é mais comum no Brasil, presente em

Quadro 5

Bases teóricas dos programas de promoção da saúde do idoso.

\begin{tabular}{lccc}
\hline Bases teóricas & & No estudos & \\
\hline & Internacionais & no Brasil & Total \\
\hline Educação crítica (Paulo Freire) & 1 & 3 & 4 \\
Teoria da aprendizagem social (Bandura) & 2 & 0 & 2 \\
Modelo de bem-estar ecológico (Ruffing-Rahal) & 2 & 0 & 2 \\
Teoria do suporte social & 1 & 1 & 2 \\
Pesquisa participante & 1 & 1 & 2 \\
Promoção da Saúde e empowerment & 1 & 1 & 2 \\
Modelo de envelhecimento bem-sucedido & 1 & 0 & 1 \\
Teoria Azjen (comportamento planejado) & 1 & 0 & 1 \\
Kanfer's Model & 1 & 0 & 1 \\
Teoria da organização comunitária & 1 & 0 & 1 \\
Modelo de aderência & 1 & 0 & 1 \\
Feminismo & 1 & 0 & 1 \\
Teoria das necessidades (Virgínia Hendersen) & 0 & 1 & 1 \\
Cuidado cultural (Madeleine Leininger) & 0 & 1 & $\mathbf{2 2}$ \\
Total & $\mathbf{1 4}$ & $\mathbf{8}$ & \\
\hline
\end{tabular}


três experiências, enquanto outras, embora sem mencionar esta filiação teórica, trazem elementos próximos ao campo da Educação Popular em Saúde, como fortalecimento dos sujeitos e de sua auto-estima, rompimento com o modelo biologicista e fragmentação das práticas, problematização dos limites individuais e coletivos para o cuidado em saúde.

A experiência de outros países é formatada predominantemente por teorias comportamentais clássicas no campo da educação e saúde e, em menor grau, por abordagens contemporâneas sobre envelhecimento bem-sucedido e bem-estar ecológico. Apenas o estudo de Minkler (1992) faz menção à pedagogia crítica e tem uma perspectiva de organização comunitária. É ele também a única referência ao debate contemporâneo sobre promoção da saúde, no sentido de incorporar preocupações com questões de organização política da população envolvida. No Brasil, igualmente, um estudo articula-se explicitamente com este debate, na ótica predominante do empowerment em nível individual (Teixeira, 2002).

Os quadros 6 e 7 apresentam uma síntese dos programas revisados, da ótica como estruturam e fundamentam suas ações.

\section{Desenho metodológico e principais resultados}

Diferentes propósitos e estratégias metodológicas norteiam os estudos analisados. Dos 11 estudos internacionais, nove utilizam métodos quantitativos e envolvem grande número de idosos (média de 450), freqüentemente para avaliações do tipo quase-experimental. Neste modelo é feita a comparação de um grupo participante do programa (grupo experimental GE) com outro não participante (grupo controle - GC) visando aferir os efeitos da intervenção. Seis estudos utilizam esta metodologia, todos com follow-up ou reavaliações em curto ou médio prazo, e os demais distribuem-se igualmente em survey pós-intervenção, estudo transversal longitudinal, análise de variáveis em uma coorte, avaliação qualitativa e estudo de caso.

No Brasil, como já comentado, vários estudos são relatos de experiências com aspectos avaliativos de base qualitativa, mais ou menos desenvolvidos, e não propriamente pesquisa com fins de avaliação. Os demais são dois estudos descritivos de avaliação da receptividade do programa, e quatro estudos qualitativos, dois dos quais baseados em pesquisa participante.
Os instrumentos utilizados nos estudos quantitativos são diversos, embora com conteúdos semelhantes, predominando o uso de escalas e análises baseadas em score para aferir resultados atitudinais e comportamentais. Os estudos qualitativos que apresentam metodologia própria, além do relato da experiência ou estudo de caso, são os de Ruffing-Rahal (1993) e, no Brasil, os de Teixeira (2002) Nicola (1999) e Portella (1999).

No desenho metodológico é comum a avaliação de mais de um aspecto do programa. O quadro 8 mostra as dimensões avaliadas segundo sua recorrência nos estudos:

Os principais resultados dos estudos segundo o foco da avaliação são a seguir sintetizados: - Receptividade dos idosos: é unânime a avaliação positiva dos idosos quanto às atividades desenvolvidas nos programas. Os aspectos destacados são a ampliação de conhecimentos, a oportunidade de interações sociais e, no estudo de Almeida et al. (1998) particularmente, a afetividade e o bom tratamento recebido.

- Melhora de indicadores psicossociais: nos dois estudos brasileiros, de base qualitativa, é comum a referência a mudanças positivas em termos de valorização do idoso, ampliação da rede social e melhoria das relações familiares e sociais. Teixeira (2002) destaca ainda o sentimento de integridade e maior controle sobre a vida. Nas demais avaliações, todas com base em estudos caso-controle, há ponderações diferentes em função do leque maior de aspectos analisados e de dados empíricos não convergentes. Excluindo o trabalho de Brice et al. (1996), em que os efeitos sobre a saúde subjetiva e senso de bem-estar são evidentes, os outros mostram diferentes padrões de respostas em um mesmo estudo, incluindo-se a ausência de efeitos, vista como estabilização benéfica no curto prazo. Mesmo sem o incremento positivo esperado em alguns aspectos, é ressaltada a redução maior no grupo controle ocorrida quanto ao sentimento de autocontrole, satisfação com vida e bem-estar. Ruffing-Rahal (1994) e Elder (1995). - Aderência às recomendações comportamentais: os resultados encontrados são bem variados. No estudo de Brice et al. (1996), é encontrado um forte efeito, mas os demais transitam entre a tendência de estabilização das condições iniciais (Ruffing-Rahal, 1994) ou de pequeno ganho em termos de mudanças favoráveis nas práticas de saúde (Elder et al., 1995). O dado apresentado por Rogers et al. (1992) é o de que $1 / 3$ dos participantes considerou as ati- 
Quadro 6

Estruturação e bases teóricas dos Programas de Promoção da Saúde do Idoso, internacionais, no período 1990-2002.

1o autor/ano/local Ações

Parcker (2002) Promoção da Saúde Baseada na Fé

Alabama / EUA

Objetivos

- Promover envelhecimento bem-sucedido (EBS)

- Socializar conhecimento sobre EBS e destacar papel da espiritualidade

- Desenvolver liderança, trabalho e voluntariado entre idosos

- Ampliar discussões sobre preparar o envelhecimento
Bases teóricas / princípios

- Modelo de envelhecimento bemsucedido - Rowe e Kahn

- Caráter preventivo e promocional do suporte social oferecido pelas religiões

- Importância da parceria entre instituições médicas e acadêmicas com as comunidades baseadas na fé

\section{Estratégias metodológicas}

- Planejamento com representantes de +30 igrejas locais

- Evento sobre EBS para 500 pessoas (idosos e seus filhos adultos afiliados a organizações cristãs) $=>$ Atividades diversas oferecidas (sessões temáticas, workshops, screenings)

- Temas: comportamentos relacionados a efeitos positivos de saúde, engajamento ativo com a vida, prevenção de doença e incapacidade, transferência intergeracional de sabedoria, programas e serviços para idosos, prática espiritual, dentre outros
Kocken (1998)

Roterdão / Holanda

\section{Curso "Envelhecimento Bem-Sucedido"}

\section{Objetivos}

- Empoderar adultos idosos para participar socialmente e promover seu bem-estar

\section{Bases teóricas / princípios}

- Teoria de Ajzen (comportamento planejado) e Teoria da aprendizagem social (Bandura)

- Modelo teórico propõe que a participação social relaciona-se a: 1) atitude quanto ao envelhecimento;

2) influência da opinião social; 3) auto-eficácia em engajar-se em novas atividades

\section{Estratégias metodológicas}

- Grupo com cerca de 20 pessoas, coordenadas por educadores em saúde - seniores previamente treinados. Programação de 4 encontros (uma vez / semana)

- 1a sessão: determinantes do EBS: suporte social, estilos de vida saudáveis, renda e auto-eficácia

- Grupo escolhia os próximos temas (sono, memória, medicações, moradia, osteoporose, atividade física, expansão da população idosa em diferentes culturas foram os temas escolhidos)

- Dinâmica: introdução do coordenador / discussão

- Informações sobre estilos de vida saudáveis / questões de saúde para discutir a participação social

- Idosos educadores (credibilidade da informação) 
Quadro 6 (continuação)

1o autor/ano/local Ações

Fox (1997) Programa Cuidado de Saúde Preventiva para o Envelhecimento

Califórnia / EUA

\section{Objetivos}

- Aumentar a aderência dos idosos às ações preventivas

\section{Bases teóricas / princípios}

- Modelo da aderência (papel mais eqüitativo para o cliente / composição de metas conjuntas no cuidado à saúde)

- Prevenção primária

(força-tarefa de serviços preventivos, 1996/EUA)

\section{Estratégias metodológicas}

- Avaliação de saúde ampla => coleta de dados (história da saúde, avaliação nutricional, exame físico limitado)

- Aconselhamento para riscos de saúde identificados e necessidades de saúde referidas ("Quais os comportamentos de saúde que eles estão mais propensos e são capazes de mudar") / encaminhamentos para demais questões (registram e checam após 3 meses por telefone e nas visitas seguintes)

- Fornecem os resultados do screening e panfletos
Brice (1996)

Nova York / EUA

\section{STAYWELL Program}

\section{Objetivos}

- Interferir positivamente em crenças e comportamentos em saúde
Bases teóricas / princípios

- Base epidemiológica e relevância da prevenção primária ou secundária em relação à terciária

\section{Estratégias metodológicas}

- Programa de Promoção da Saúde, baseado em conteúdos do Healthy People 2000

- 8 sessões (2,5 horas, caráter semanal, 20 a 25 idosos)

- Dinâmica da sessão: exposição, seguida de sessões de exercício anaeróbico, administração estresse, nutrição, técnicas de relaxamento e lanche nutritivo

- Temas: saúde física (prevenção e coping de doença cardíaca, diabetes e câncer), saúde mental, saúde oral, atividade física, nutrição, álcool e drogas, dentre outros 
Quadro 6 (continuação)

1o autor/ano/local Ações

Elder (1995)

Califórnia / EUA

Intervenção em Promoção da Saúde

Objetivos

- Avaliar efeitos de serviços preventivos com beneficiários do Medicare

\section{Bases teóricas / princípios}

- Teoria da aprendizagem social (Bandura)

- Kanfers's model (autocontrole e auto-mudança)

\section{Estratégias metodológicas}

- 8 workshops (duas horas, caráter semanal, 25 idosos)

- Growing younger: saúde física (exercício, nutrição, relaxamento e autocuidado relativo a problemas médicos comuns); e Growing wise: memória, atenção mental, coping para perdas, escolhas e autoconfiança

- Aconselhamento anual individualizado, de 15 minutos, consentido por contrato, visando ao estabelecimento de metas; aconselhamento por telefone e resolução de problemas

- Forneciam relatório individualizado, amplo, relevante para as metas, e mais dois manuais que completavam os workshops

\section{Objetivos}

- Testar factibilidade de prover serviços de prevenção de doenças e promoção da saúde (PS) aos beneficiários do Medicare de maneira custo-benefício
Bases teóricas / princípios

- Referência ao debate sobre a polêmica em torno da efetividade da Promoção da Saúde com idosos
Estratégias metodológicas

- Serviços oferecidos aos beneficiários do Medicare, com objetivo de pesquisa, através dos médicos da atenção primária

- Após 8 semanas da avaliação baseline por telefone, os idosos passavam pela clínica de screenings (8 estações) e orientações sobre PS

- G As atividades começavam com conversa breve e introdutória sobre comunicação médico-paciente, imunizações e autoajuda e duravam cerca de 4 horas. Serviços não-invasivos e oferecidos por não-médicos

- G aconselhamento individual sobre: parar de fumar, alimentação, terapia física e ocupacional, trabalho social, adesão à medicação, exercício, saúde oral e higiene 
Quadro 6 (continuação)

1o autor/ano/local Ações

Ruffing-Rahal (1994) Grupo de Promoção da Saúde e Bem-Estar com Mulheres na Comunidade Ohio / EUA

\section{Objetivos}

- Incrementar práticas de saúde, bem estar espiritual, psicológico e integração social
Bases teóricas / princípios

- Modelo de bem-estar ecológico (Ruffing-Rahal, 1991)

- Dimensões-chave do bem-estar cotidiano: atividade, afirmação e síntese
Estratégias metodológicas

- 26 sessões semanais, de uma hora, durante seis meses, com dois facilitadores (um dos quais a investigadora)

- Dinâmica: parte informativa, diálogo entre o grupo, demonstração de habilidades específicas de bem-estar. Em cada sessão contemplavam ações relativas às três variáveis dependentes incorporadas na análise

- Salas com cadeiras em círculos. Cerca de 14 participantes

- Temas sobre saúde, autocuidado e interações sociais (lista 26 tópicos)

\section{Ruffing-Rahal (1993) Grupo Welness Life-Care}

Ohio / EUA

\section{Objetivos}

- Possibilitar a interação entre os idosos interessados em bem-estar, saúde e autocuidado
Bases teóricas / princípios

- Modelo de bem-estar ecológico (Ruffing-Rahal, 1991)

- Três orientações teóricas relativas a grupo e a processo de grupo: feminismo, grupo como suporte e grupo focal
Estratégias metodológicas

- Grupo semanal com mulheres idosas

- Participação regular de 12 a 14 mulheres

- Partilha de informação, de problemas e preocupações comuns, aprendizagem interpessoal, coesão grupal "instilação da esperança"
Watkins (1993)

Arizona / EUA

\section{Project AGE WELL}

\section{Objetivos}

- Ampliar conhecimento básico de saúde

- Ampliar uso de screenings e imunizações

- Ajudar as pessoas a modificar comportamentos não saudáveis

- Prover dados longitudinais para avaliar mudanças
Bases teóricas / princípios

- Não menciona
Estratégias metodológicas

- Ações interdisciplinares em vários locais, envolvendo atividades educativas $\mathrm{e}$ avaliações individuais anuais

- Três ações básicas: sessões de exercício ( $3 \mathrm{x} /$ semana); educação em saúde sobre fatores de riscos ${ }^{\star}$; tópicos de saúde (sessões semanais)

- Grupo de suporte administração de estresse

* Temas baseados em surveys prévios: cuidado com a saúde, saúde cardiovascular, prevenção e controle do câncer, osteoporose e prevenção de fratura, saúde mental e medicação consciente, dentre outros, conforme a necessidade 
Quadro 6 (continuação)

1o autor/ano/local Ações

Rogers (1992)

Programa de Promoção da Saúde do Idoso Baseado em Comunidade

Nova York / EUA

Objetivos

- Transmitir conhecimentos gerais e prover conhecimentos específicos e aconselhamento quanto às necessidades de prevenção e promoção da saúde dos idosos

\section{Bases teóricas / princípios}

- Referência ao debate sobre a polêmica em torno da efetivida de da Promoção da Saúde com idosos e de como melhor prover os serviços

\section{Estratégias metodológicas}

- Recrutaram 500 idosos de um seguro privado de saúde e de centros de idosos. Atividades oferecidas: 1) classes de educação em saúde - dois encontros sobre cada tópico no decorrer de dois anos) => temas: doenças e questões gerais (p. ex: aposentadoria, drogas, nutrição, recursos comunitários, segurança pessoal e ambiental, sexualidade);

2) serviço de administração de casos - avaliação de screening compreensiva, discussão do caso em equipe, retorno para o idoso e acompanhamento por um administrador de casos

\section{Minkler (1992) Tenderloin Senior Organization Project}

\section{Objetivos}

- Realçar "habilidade de resposta" / capacidade individual e comunitária para responder efetivamente às próprias necessidades e desafios do meio
Bases teóricas / princípios

- Teoria do suporte social

- Educação crítica (Paulo Freire)

- Teoria da organização comunitária

- Princípios do empowerment (em dois níveis: individual $=>$ coping, senso de controle e satisfação com a vida; e competência comunitária)

\section{Estratégias metodológicas}

- Abordagem comunitária com idosos pobres de hotéisresidência

- Formação de grupos em oito hotéis, a partir do screening de PA e lanche para facilitar a integração

- Grupos pequenos: média de 12 idosos, com sessões semanais e coordenados por dois facilitadores

- Dinâmica: diálogo e participação para identificação de problemas comuns e compartilhamento de soluções; fortalecimento da solidariedade grupal, problematização e organização para a ação social

- Temas definidos por cada grupo: começar onde as pessoas estão 
Quadro 7

Estruturação e bases teóricas dos Programas de Promoção da Saúde do Idoso, no Brasil, no período 1990-2002.

\begin{tabular}{|c|c|c|c|}
\hline 1 o autor/ano/local & \multicolumn{3}{|l|}{ Ações } \\
\hline \multirow{2}{*}{$\begin{array}{l}\text { Teixeira (2002) } \\
\text { Rio de Janeiro/RJ }\end{array}$} & \multicolumn{3}{|c|}{ PROVE - Programa de Valorização do Envelhecer } \\
\hline & $\begin{array}{l}\text { Objetivos } \\
\text { - Promover espaço onde idosos, } \\
\text { possam discutir assuntos } \\
\text { relativos à longevidade e à } \\
\text { construção positiva da velhice }\end{array}$ & $\begin{array}{l}\text { Bases teóricas / princípios } \\
\text { - Promoção da Saúde } \\
\text { (empowerment e autonomia } \\
\text { positiva) } \\
\text { - Gerontologia } \\
\text { - Psicologia do envelhecimento e } \\
\text { teoria de grupo } \\
\text { - Pedagogia de Paulo Freire } \\
\text { (conscientização, educação } \\
\text { libertária, transformação dos } \\
\text { sujeitos, humanização) }\end{array}$ & $\begin{array}{l}\text { Estratégias metodológicas } \\
\text { - Grupo de Encontro de Idosos, } \\
\text { realizado através de trabalho } \\
\text { interdisciplinar, com as seguintes } \\
\text { características: 1) gerenciamento } \\
\text { democrático do projeto; } \\
\text { 2) abordagem conceitual e } \\
\text { discussão de temas propostos } \\
\text { pelos usuários; } 3 \text { ) palestras inte- } \\
\text { rativas (mensais) de orientação } \\
\text { em saúde, baseadas na Cartilha } \\
\text { Viva bem a idade que você tem } \\
\text { - Abordagem de temas relaciona- } \\
\text { dos à saúde no envelhecimento } \\
\text { - G conexão entre saúde e } \\
\text { condições de vida }\end{array}$ \\
\hline
\end{tabular}

Diogo (2000)

Campinas / SP

GRASI - Grupo de Atenção à Saúde do Idoso

Objetivos Bases teóricas / princípios

- Contribuir para a compreensão do processo de envelhecimento e dos problemas a ele relacionados
- Concepções sobre educação para o autocuidado no campo da enfermagem geriátricogerontológica
Estratégias metodológicas

- Grupo de 4 sessões para idosos e seus familiares

- Realizaram 4 grupos, envolvendo 18 idosos

- Técnicas grupais: desenho, relaxamento, relatos de experiências, exposição oral com apoio de cartazes

- Definição dos temas com os participantes no 1o encontro. Abordaram: envelhecimento, memória, alterações visuais, quedas, sono, pele, dificuldade de movimentação e solidão
Lopes(1999)

Porto Alegre / RS

Ambulatório de Promoção da Qualidade de Vida

\footnotetext{
Objetivos

- Desencadear processo de educação em saúde para a promoção da qualidade de vida, na perspectiva de visão integral dos sujeitos atendidos
}

\author{
Bases teóricas / princípios \\ - Referência conceitual crítica \\ sobre a consulta de enfermagem \\ e seu cunho educativo
}

\author{
Estratégias metodológicas \\ - Consulta de enfermagem \\ centrada na educação em saúde \\ e trabalho multidisciplinar / \\ Grupo de caminhada / Grupo \\ da Terceira Idade \\ - Atividade educativa mensal \\ (Conversando sobre...) $=>$ \\ temas: osteoporose, alimentação, \\ saúde e qualidade de vida, \\ climatério, atividade física
}


Quadro 7 (continuação)

\begin{tabular}{|c|c|c|c|}
\hline \multirow{2}{*}{$\begin{array}{l}\text { 1o autor/ano/local } \\
\text { Rodrigues (1999) } \\
\text { São Paulo, Santos, } \\
\text { Sorocaba e } \\
\text { Ribeirão Preto / SP }\end{array}$} & \multicolumn{3}{|l|}{ Ações } \\
\hline & \multicolumn{3}{|l|}{ Programa Viver Bem com Saúde } \\
\hline Ribeirão Preto / SP & $\begin{array}{l}\text { Objetivos } \\
\text { - Implementar modelo } \\
\text { de educação que incentive } \\
\text { o idoso para a PS, favoreça sua } \\
\text { autonomia e independência } \\
\text { e o auxilie no seu processo } \\
\text { de autocuidado }\end{array}$ & $\begin{array}{l}\text { Bases teóricas / princípios } \\
\text { - Referência à Política Nacional } \\
\text { do Idoso (1994) no que tange } \\
\text { ao desenvolvimento de ações } \\
\text { preventivas, curativas e } \\
\text { promocionais }\end{array}$ & $\begin{array}{l}\text { Estratégias metodológicas } \\
\text { - Ciclo de palestras para o público } \\
\text { acima de } 44 \text { anos, divulgado } \\
\text { pela mídia e correio } \\
\text { - Primeiro encontro para iden- } \\
\text { tificação dos temas de interesse } \\
\text { do grupo, através de técnica de } \\
\text { interação em grupo } \\
\text { - Organização dos temas em sete } \\
\text { módulos: relação médico-paciente, } \\
\text { saúde bucal, perdas sensoriais e } \\
\text { insônia; problemas neurológicos; } \\
\text { solidão, depressão, dor e cuidados } \\
\text { com medicamentos; problemas } \\
\text { cardíacos; perdas, climatério, } \\
\text { cuidados com a próstata e sexua- } \\
\text { lidade; alimentação; problemas } \\
\text { ortopédicos } \\
\text { Envolveram no total } 976 \\
\text { participantes }\end{array}$ \\
\hline
\end{tabular}

Nicola (1999)

Rio Grande / RS

\section{Ação Educativa Gerontológica}

\section{Objetivos}

- Valorizar a integração do adulto idoso na família e na comunidade; propor ações para transformações sociais que beneficiem os idosos; e preparar animadores para o trabalho com essa população
Bases teóricas / princípios

- Teorias sobre o desenvolvimento humano (Cita Comfort, Maslow, Mosquera)

- Conceitos sobre grupos

- Educação continuada

- Educação popular gerontológica

\section{Estratégias metodológicas}

- 1a etapa: dois cursos de formação de animadores de grupos de ação educativa gerontológica

- 2a etapa: realização de grupos com idosos pelos egressos desses cursos

- 5 grupos diferenciados realizados nas comunidades de Rio Grande e São José do Norte, média de 26 membros

- (não descreve formato metodológico dos grupos) 
Quadro 7 (continuação)

\section{1o autor/ano/local Ações}

Portella (1999) Grupo Cuidar para um Envelhecer Saudável

Passo Fundo / RS

Objetivos

- Compartilhar saberes que contribuam para um envelhecer saudável
Bases teóricas / princípios

- Referencial do Cuidado Cultural (Madeleine Leininger)

- Concepção pedagógica de Paulo Freire
Estratégias metodológicas

- Grupo quinzenal, de 90 minutos, com mulheres rurais

- Diálogo reflexivo sobre as práticas culturais de saúde

- Quatro etapas do processo de trabalho da enfermagem:

1) conhecendo o grupo; 2) identificando e refletindo sobre as práticas culturais de saúde; 3) discutindo e construindo com o grupo novas práticas; e 4) analisando o processo de mudança das práticas culturais de saúde
Almeida (1998)

Fortaleza / CE

Grupo Vida

\section{Objetivos}

- Desenvolver a auto-estima e reforçar a dignidade do idoso; reativar suas capacidades e reintegrá-lo à família; fortalecer convívio saudável e habilitá-lo a realizar práticas afirmativas de vida
Bases teóricas / princípios

- Teoria das necessidades (Virgínia Henderson)
Estratégias metodológicas

- Grupo semanal, de duas horas, com 50 pessoas inscritas, entre 48 e 81 anos, com participação média de 20 pessoas

- Metodologia participativa: utilização de dinâmicas vivenciais.

- Temas iniciais dirigidos à saúde: dificuldades próprias da idade, perdas relacionais e dificuldades para novos vínculos, carência de recursos materiais e limitações físicas em ambiente inapropriado. Ampliação para outros 
Quadro 7 (continuação)

1o autor/ano/local Ações

Lima (1996) Programa de Atenção à Saúde no Envelhecimento

São Paulo / SP

Objetivos

- Ampliar consciência sobre o envelhecer, associando-o aos modos de relação do idoso ante os cuidados com sua saúde; requalificar aspectos ligados à qualidade de vida dos idosos, discernindo possibilidades e limites nos planos individuais e sociais
Bases teóricas / princípios

- Referências conceituais a documentos da OPAS e OMS sobre envelhecimento
Estratégias metodológicas

- Organização das atividades assistenciais segundo lógica programática e atividade educativa grupal

- Grupo Saúde e Envelhecimento: 1) grupos pequenos ( 8 a 10 pessoas), com reuniões semanais de uma hora e trinta minutos, com duração de 16 encontros; 2) coordenação de dois profissionais de nível superior; 3) idade mínima para o programa $=55$ anos.
Telarolli Jr. (1997) Araraquara / SP

\section{Projeto Senior \\ Ciclo de palestras e minicursos para a Terceira Idade}

Objetivos Bases teóricas / princípios

- Oferecer atividades educativas e de lazer à população idosa através da abertura de espaços da universidade
- Referência à importância dos grupos de convivência e dos programas educativos para idosos na manutenção da saúde e da qualidade de vida desta população

\section{Estratégias metodológicas}

- Programação de 4 meses, incluindo 29 palestras ( 3 por turno, 50 minutos em média cada) sobre prevenção de problemas de saúde, questões sobre o envelhecimento e temas gerais

- Três minicursos práticos (6 horas) sobre: 1) produção caseira de derivados de leite; 2) introdução à fitoterapia; e 3) produção caseira de queijo minas e frescal

- 96 participantes (incluindo público acima de 45 anos. Cerca da metade dos inscritos tinha menos de 60 anos) 
Quadro 8

Dimensões avaliadas nos programas de promoção da saúde do idoso.

\begin{tabular}{lccc}
\hline Dimensões da avaliação & No estudos & \\
\hline & Internacionais & No Brasil & Total \\
Receptividade dos idosos & 2 & 4 & 6 \\
Melhora de indicadores psicossociais & 4 & 2 & 6 \\
Aderência às recomendações comportamentais* & 5 & 0 & 5 \\
Análise do processo educativo & 2 & 3 & 5 \\
Repercussões acerca da intenção de mudanças & 1 & 1 & 2 \\
Verificação de variáveis relacionadas às participação & 2 & 0 & 2 \\
Melhora da performance dos animadores & 0 & 1 & 1 \\
Total & $\mathbf{1 6}$ & $\mathbf{1 1}$ & $\mathbf{2 7}$ \\
\hline
\end{tabular}

* Incluem as referências a práticas de saúde e de autocuidado.

vidades educativas muito ou extremamente úteis em melhorar atitudes e capacitar para o autocuidado. Já o trabalho de Fox et al. (1997) não evidencia exatamente o quanto houve de melhora mas analisa que esta foi maior com uma intervenção "realçada" (aconselhamento individualizado e plano escrito) em relação à prática de simples recomendações verbais.

- Análise do processo educativo: Ruffing-Rahal (1993) e Minkler (1992) são autoras que abordam esta dimensão, através de metodologias qualitativas. No primeiro caso, o grupo educativo com mulheres idosas é avaliado como espaço que representa o exercício de três dimensões: ritual, celebração e comunidade. Numa perspectiva semelhante embora mais explicitamente política, Minkler (1992) considera que o programa, para além dos ganhos específicos com as ações realizadas, teve como principal resultado o aumento da competência comunitária e do senso de controle dos idosos sobre suas próprias vidas. Nos estudos nacionais, Almeida et al. (1998) e Portella (1999) aproximam-se da linha desses trabalhos e destacam o grupo como espaço de compartilhamento, de expressão de práticas culturais, de favorecimento da rede de apoio social. Da ótica de programas educativos mais formais, baseado em palestras, os dados de Rodrigues et al. (1999) revelam boa aceitação do processo pedagógico, incluindo aqui a abertura dos palestrantes para esclarecer dúvidas. Por outro lado, os resultados de Telarolli Jr. et al. (1997) sugerem o questionamento de modelo educativo eminentemente expositivo e saturado de recursos audiovisuais, avaliados como cansativos por 2/3 dos participantes.

- Repercussões acerca da intenção de mudanças: nos dois estudos que investigam este aspec- to é elevado o percentual de participantes que apontam intenção de fazer mudanças em sua vida a partir da influência do programa. Cerca de $80 \%$ das pessoas no trabalho de Rodrigues et al. (1999) referem esta disposição, no caso específico quanto à "conduta de saúde" (por exemplo, alimentação e atividade física), e percentuais semelhantes são encontrados na pesquisa de Parcker et al. (2002), com a particularidade, aqui, de comparação entre a população afro-americana e branca, com valores de 97 e $80 \%$, respectivamente.

- Verificação de variáveis relacionadas à participação: melhor status de saúde é associado com maior participação nos programas de promoção da saúde. Entretanto, como mostra o estudo de Schweitzer (1994), quando verificadas as práticas preventivas prévias, conclui-se que os programas têm potencial de atrair também pessoas não engajadas em prevenção.

- Melhora da performance dos animadores: um único estudo avalia este aspecto, posto ser a capacitação um dos objetivos do programa. Os dados obtidos indicam a efetividade da intervenção quanto a esse propósito (Nicola, 1999).

Quando a dimensão avaliativa limitou-se à referência sobre um possível impacto do trabalho no modelo assistencial, foram destacadas a sua contribuição para a realização de práticas menos fragmentadas e dissociadas da realidade social e política (Lopes et al., 1999) e para uma relação educativa em que os sujeitos possam problematizar as questões que vivenciam e, juntos, vislumbrar os encaminhamentos/ respostas para seus problemas (Lima et al., 1996).

Os quadros 9 e 10 apresentam uma síntese da proposta metodológica e dos resultados da avaliação dos programas. 
Quadro 9

Desenho metodológico e resultados da avaliação dos Programas de Promoção da Saúde do Idoso, internacionais, no período $1990-2002$.

\begin{tabular}{lll}
\hline 1o autor/ano/local & Desenho da avaliação & Principais resultados \\
\hline Parcker (2002) & - Survey pós-conferência com 135 pessoas (27\%) & - $98 \%$ avaliaram o evento como excelente ou bom \\
Alabama / EUA & que responderam ao questionário de avaliação & - Intenção de fazer mudanças a partir do evento foi \\
& do Encontro & maior entre os afro-americanos $(97 \%)$ do que na \\
& & população branca $(80 \%)$
\end{tabular}

Kocken (1998) • Avaliação quase-experimental da efetividade Roterdão / Holanda do curso (Foi efetivo em melhorar os determinantes da participação social, suporte social e bem-estar dos seus membros?)

- Convidaram os idosos da cidade pelo correio $(55-79$ anos $)=>320$ inscritos $(\mathrm{GE}=138$ e GC $=182)$

- Pré-teste ( $\mathrm{t} 0$ ), pós-teste ( $\mathrm{t} 1)$ e após 3 meses (t2)

- Escalas para medir atitudes, participação social, suporte social, bem-estar e saúde subjetiva
- $\mathrm{GE}=71$ e $\mathrm{GC}=75>>51 \%$ e $41 \%$ retorno follow up

- Efeitos em algumas áreas, mas pequenos:

1) diferença significativa entre os grupos quanto à percepção da influência societal na posição do idoso;

2) efeito sobre suporte social e saúde subjetiva

- Não houve diferença significativa quanto à atitude e à participação social.

\begin{tabular}{ll}
\hline Fox (1997) & Avaliação quase-experimental da efetividade do \\
Califórnia / EUA & aconselhamento com e sem orientação escrita 237 \\
& $(\mathrm{GE}=118 \mathrm{GC}=119)$ \\
& Aconselhamento individualizado no GE, com plano \\
& escrito detalhado com tempo e metas, e apenas \\
& recomendações verbais no GC \\
& Reavaliação em 3 e 12 meses depois \\
& - Utilização de cinco instrumentos
\end{tabular}

- Amostra relativamente saudável (+ de 80\% sem prejuízo em AVDs e sem internação no último ano)

- As recomendações que envolviam mudanças comportamentais foram mais difíceis do que as que envolviam screening (uso serviços). Dentre as barreiras para aderência, as econômicas foram as destacadas ( $5 \%$ no GE e $13 \%$ no GC)

- Maior aderência no GE: confirma > efetividade da ação personalizada e cooperativa

\section{Brice (1996)}

Nova York / EUA
- Estudo quase-experimental para avaliar efetividade do programa a partir de dados empíricos

- Convidaram 146 adultos (55 anos ou +) de Centros de Cidadãos Seniores

- Instrumentos de avaliação de crenças e comportamentos de saúde antes do programa e nove meses depois: 1) index de crenças saudáveis (score de 0-32);2) index de comportamento saudável ( " 0 -24)

- >> altos scores representam estilo de vida saudável.
- $\mathrm{GE}=96$ e $\mathrm{GC}=50=>70 \%$ retorno no follow-up

- GE com scores mais altos na crença de que mudança de comportamento pode ter impacto na saúde

- Resultado também quanto ao index de comportamento $=>$ efeito de magnitude suficiente para prover evidência clínica e política

- Consumo de medicação reduziu no GE e não no GC. Efeito positivo verificado na saúde subjetiva e senso de bem-estar $=>$ crença na auto-eficácia quase dobrou no GE

- Forte efeito do programa sobre crenças e comportamentos em saúde.

\section{Elder (1995) Califórnia / EUA}

- Avaliação quase-exerimental dos efeitos longitudinais de serviços preventivos com beneficiários do Medicare

- Instrumentos: "Avaliação de risco de saúde" (comportamentos, hábitos de vida, sintomatologia e história de doenças auto-referidas, status de saúde e escalas de qualidade do bem-estar e de depressão)

- Compararam dados do baseline com as avaliações aos 24 e 48 meses

- Construíram variáveis outcomes e analisaram dados para pressão sangüínea, exercício e nutrição Obs: baixa renda e declínio da saúde pessoal foram principais motivos das perdas
- Dos 1.800 participantes, 798 concluíram todas as avaliações (critério incluía também 70\% de presença nos workshops)

- A 1a meta escolhida no GE foi o aumento da atividade física (40\%) e do consumo de vegetais

- Efeito de redução da pressão arterial ocorreu em ambos os grupos. Efeitos positivos sobre a flexibilidade e a atividade aeróbia

- Índice de massa corporal não se alterou. Ganhos nutricionais não se sustentaram após o 30 ano

- Percepção de controle da própria saúde diminuiu nos grupos (fator idade), porém mais no GC

- Dados sugerem que efeitos são maiores durante a intervenção e que a aderência enfraquece com o tempo

- Concluem que houve modesto efeito e que, portanto, os resultados oferecem modesto suporte para implementação de programas 
Quadro 9 (continuação)

\begin{tabular}{|c|c|c|}
\hline $1 \mathrm{o}$ autor/ano/local & Desenho da avaliação & Principais resultados \\
\hline $\begin{array}{l}\text { Schweitzer (1994) } \\
\text { Califórnia / EUA }\end{array}$ & $\begin{array}{l}\text { - Ensaio clínico aleatório para avaliar efeitos do } \\
\text { screening e das atividades de promoção da saúde } \\
\text { - Instrumentos: Survey por telefone (30 a } 40 \\
\text { minutos) } \\
\text { - Amostra de } 1911 \text { >> dois grupos (GE = } 973 \text { e GC } \\
=938 \text { ) } \\
\text { - Analisaram } 17 \text { comportamentos de saúde e } \\
\text { compararam dados do grupo que completou a } \\
\text { intervenção ( } 71 \% \text { de retorno) e dos que não } \\
\text { compareceram ao segundo convite }\end{array}$ & $\begin{array}{l}\text { - Os que não participaram da Clínica de Screening } \\
\text { e de PS reportavam status de saúde mais pobre } \\
\text { em vários indicadores } \\
\text { - Saúde foi associada com participação (os mais } \\
\text { debilitados participam menos). Pessoas saudáveis } \\
\text { parecem ser mais engajadas em prevenção, mas } \\
\text { não se pode determinar a causalidade (o que vem } \\
\text { primeiro) } \\
\text { - Grupos não diferiram quanto à participação prévia } \\
\text { em práticas de saúde preventivas => sugere que } \\
\text { as ações de PS podem atrair os que potencialmente } \\
\text { podem se beneficiar e não apenas os já aderidos }\end{array}$ \\
\hline
\end{tabular}

Ruffing-Rahal (1994) • Avaliação pós seis meses de intervenção com Ohio / EUA desenho quase-experimental (grupos não equivalentes, mas comparáveis)

- Amostra com 28 idosos recrutados na mesma área urbana $(\mathrm{GE}=14$ e GC $=14)$

- Três instrumentos: inventário de estilo de vida dos idosos (26 itens / escala de 0 a 4), inventário de integração (50 itens / 6 pontos), medidas de auto-avaliação de bem-estar e de integração social
- Scores médios altos no baseline para todas as medidas

- Não houve incremento significativo no GE como hipotetizado

- Houve redução nos scores de práticas de saúde e bem-estar no GC, assim como na satisfação com a vida

- Hipótese de melhora do GE não foi suportada mas estabilidade das condições investigadas sugere "permanência de efeito" ou "influência sustentada" => programa parece ter efeito de estabilização benéfico no curto prazo

\begin{tabular}{ll}
\hline Watkins (1993) & Avaliação de variáveis relacionadas à participação \\
Arizona / EUA & dos idosos ao longo de 5 anos do projeto \\
& Forma de medir a participação = soma da \\
& participação (medida por hora) em todas as \\
& atividades \\
& Amostra de 224 sujeitos que fizeram o screening \\
& inicial e divisão desta em 4 grupos conforme nível \\
& de participação \\
& Comparação de quatro grupos conforme o nível \\
& de participação \\
& Análise de variáveis potencialmente influentes
\end{tabular}

Watkins (1993)

Ruffing-Rahal (1993) • Avaliação qualitativa do processo de um grupo Ohio / EUA
- Intensidade da participação foi significativamente relacionada à socialização e à saúde dos participantes

- Isolamento social, pobre tolerância ao exercício e problemas de saúde eram características das pessoas menos propensas a participarem das sessões

- Entretanto, são esses idosos que mais necessitam de promoção da saúde semanal de PS com mulheres idosas

- Fonte = anotações de campo de 75 encontros semanais, digitadas logo após os encontros, em formato de três estágios: 1) contexto, inputs, processo e produtos; 2) contribuições dos participantes; e 3) dados dirigidos aos três níveis centrais do bem-estar ecológico

- Revisão das notas, usando comparação constante e indutiva. Análise baseada em codificação prévia em cada categoria
- Grupo como ritual: atmosfera de abertura, confiança e espontaneidade; período dos encontros avançou além do previsto; sinergia na interação entre os membros; escuta e diálogo

- Grupo como celebração: questões diversas eram trazidas e partilhadas; reconhecimento das qualidades e atributos das pessoas; valorização da resiliência; partilha dos aniversários e de outras transições valiosas; ganhos relativos à criatividade; insights sobre como incorporar o autocuidado nas rotinas diárias; suporte mútuo com base cristã

- Grupo como comunidade: constituição da rede social entre as mulheres; investimentos na gestão do grupo; "grupo como família" 
Quadro 9 (continuação)

\begin{tabular}{|c|c|c|}
\hline 10 autor/ano/local & Desenho da avaliação & Principais resultados \\
\hline $\begin{array}{l}\text { Rogers }(1992) \\
\text { Nova York / EUA }\end{array}$ & $\begin{array}{l}\text { - Avaliação da factibilidade do conjunto de serviços } \\
\text { oferecidos e de como este influencia } \\
\text { comportamentos auto-relatados dos participantes. } \\
\text { - Novo estudo transversal, após dois anos, com } 376 \\
\text { (retorno de 79,6\%) } \\
\text { - Entrevistas realizadas na casa do idoso por } \\
\text { profissionais não envolvidos com a implantação do } \\
\text { programa. Áreas investigadas: } 1 \text { ) aparente impacto } \\
\text { do serviço de administração de casos sobre os } \\
\text { maiores problemas de saúde; } 2 \text { ) influência } \\
\text { percebida das classes de Educação em Saúde; } 3 \text { ) } \\
\text { satisfação global com os serviços }\end{array}$ & $\begin{array}{l}\text { - Maioria avaliou as atividades educativas úteis para } \\
\text { ampliar conhecimentos e } 1 / 3 \text { como úteis para mudar } \\
\text { atitudes quanto ao desenvolvimento pessoal e ao } \\
\text { autocuidado } \\
\text { - Os idosos discutiram } 46,1 \% \text { de seus problemas } \\
\text { prioritários com os profissionais que os } \\
\text { acompanharam. Razão principal para não abordar os } \\
\text { outros foi por considerá-los irremediáveis } \\
\text { - } 86,6 \% \text { declaram-se muito ou extremamente } \\
\text { satisfeitos com os serviços / } 5,3 \text { com pouca ou } \\
\text { nenhuma satisfação } \\
\text { - Impacto global positivo. Programa parece ser factível, } \\
\text { embora um pouco caro, e ter algum impacto para } \\
\text { pessoas auto-envolvidas, mas é preciso mais trabalho } \\
\text { para responder às questões apontadas no screening } \\
\text { inicial }\end{array}$ \\
\hline
\end{tabular}

\begin{tabular}{ll}
\hline Minkler (1992) & Estudo de caso sobre os 12 anos do projeto \\
Califórnia / EUA & Tenderloin
\end{tabular}

- Ações realizadas por alguns grupos de idosos quanto à melhoria do acesso a alimentos e à segurança do bairro (projeto safehouse)

- Formação e treinamento de lideranças permitiu minimizar o papel da coordenação do projeto. Foram criadas associações de inquilinos em seis hotéis (de 800 idosos, 250 envolveram-se com as associações e 30 a 50 com atividades de liderança)

- Apesar de problemas, o projeto foi efetivo quanto ao aumento do senso de controle e da competência comunitária 
Quadro 10

Desenho metodológico e resultados da avaliação dos programas de Promoção da Saúde do Idoso, no Brasil, no período 1990-2002.

\begin{tabular}{|c|c|c|}
\hline 1 o autor/ano/local & Desenho da avaliação & Principais resultados \\
\hline $\begin{array}{l}\text { Teixeira (2002) } \\
\text { Rio de Janeiro / RJ }\end{array}$ & $\begin{array}{l}\text { - Pesquisa qualitativa com propósito de analisar o } \\
\text { processo de empoderamento dos idosos através da } \\
\text { dinâmica grupal } \\
\text { - Entrevistas e grupo focal com } 15 \text { idosos } \\
\text { participantes do projeto, há pelo menos três anos, } \\
\text { para avaliação dos efeitos da intervenção } \\
\text { - Categorias de análise: apoio social, rede social, } \\
\text { autonomia, integridade, cuidado, aprendizagem, } \\
\text { realização de projetos pessoais }\end{array}$ & $\begin{array}{l}\text { Idosos passam a se preocupar mais com o cuidado } \\
\text { à saúde e a vivenciar sentimento de integridade } \\
\text { e controle sobre suas vidas. Grupo interrompe } \\
\text { a espiral negativa do desempoderamento } \\
\text { - Ao ampliar a rede social, oferecer espaço } \\
\text { de aprendizagem e funcionar como apoio social, } \\
\text { o grupo torna-se lugar de ressignificação dos valores } \\
\text { negativos associados ao envelhecimento }\end{array}$ \\
\hline $\begin{array}{l}\text { Diogo (2000) } \\
\text { Campinas / SP }\end{array}$ & $\begin{array}{l}\text { - Relato da experiência (descrição das dinâmicas } \\
\text { utilizadas em cada encontro, com comentários } \\
\text { sobre a receptividade dos idosos, ilustrada por } \\
\text { algumas falas) } \\
\text { - Avaliação conjunta com o grupo no último } \\
\text { encontro }\end{array}$ & $\begin{array}{l}\text { - Avaliação positiva dos idosos e seus familiares } \\
\text { (gostaram e aprenderam coisas novas e importantes } \\
\text { para o enfrentamento do dia-a-dia) } \\
\text { - Problemas com falta de assiduidade dos membros } \\
\text { do grupo, atribuída à cultura de não valorização } \\
\text { de ações preventivas, problemas de moradia distante } \\
\text { (falta de transporte e de companhia), esquecimento } \\
\text { e sobreposição de compromissos. }\end{array}$ \\
\hline
\end{tabular}

\begin{tabular}{lll}
\hline Lopes (1999) & Relato de experiência, com avaliação apenas dos \\
Porto Alegre / RS & $\begin{array}{l}\text { princípios do trabalho na ótica de organização da } \\
\text { assistência segundo princípios do SUS }\end{array}$ & $\begin{array}{l}\text { Experiência pode iniciar processo de rompimento } \\
\text { com modelo biologicista de atenção à saúde e com } \\
\text { as práticas fragmentadas, dissociadas da realidade } \\
\text { social e política }\end{array}$ \\
& &
\end{tabular}

\begin{tabular}{ll}
\hline Portella (1999) & Relato de experiência baseado em observação \\
Passo Fundo / RS & participante/ reflexão-ação conjunta (pesquisador \\
& como facilitador do grupo) \\
& № de participantes por encontro foi de 8 a 16 \\
& mulheres
\end{tabular}

- Apresenta falas das mulheres sobre suas práticas culturais de saúde e as analisa de acordo com a codificação: preservar, acomodar, repadronizar

- Grupo demonstra interesse em saber mais sobre temas de saúde, interpretado como indício de aceitação de novas prática culturais de saúde

- Estudo possibilitou um processo de cuidar/educar baseado nas referências culturais do grupo

\section{Rodrigues (1999) \\ São Paulo, Santos, Sorocaba e Ribeirão Preto / SP}

- Estudo descritivo sobre os resultados de aprendizagem de 976 idosos participantes do ciclo de palestras

- Questionário aberto, auto-aplicado, ao final dos módulos temáticos (Quais os principais assuntos abordados nas palestras do módulo? Você pretende mudar a sua conduta de saúde diante da temática estudada? Este módulo correspondeu às suas expectativas? O conteúdo foi abordado de forma clara? As aulas estimularam a participação dos idosos? Como você avalia este módulo?)

- Análise de conteúdo (Bardin) para interpretação dos dados
- Todos os participantes consideraram o programa primordial para a promoção da saúde dos idosos (90\% consideraram ótimo e 10\% bom)

- Ampliação de conhecimentos e oportunidade para maior relacionamento entre os idosos

- Avaliaram positivamente as palestras (planejamento e capacitação dos profissionais, recursos audiovisuais, abertura dos palestrantes para esclarecer dúvidas e oportunidade para troca de conhecimento e maior conscientização dos problemas de saúde)

- $80 \%$ referiram intenção de mudança (p. ex., alimentação e exercício físico) 
Quadro 10 (continuação)

\begin{tabular}{|c|c|}
\hline 10 autor/ano/local & Desenho da avaliação \\
\hline $\begin{array}{l}\text { Nicola (1999) } \\
\text { Rio Grande / RS }\end{array}$ & $\begin{array}{l}\text { Pesquisa participante para verificar efeitos do } \\
\text { grupo, após um ano, sobre a auto-imagem dos } \\
\text { sujeitos, a melhoria do relacionamento familiar } \\
\text { e social o engajamento mais sadio no ambiente } \\
\text { - Investigou cinco grupos e desses compôs uma } \\
\text { amostra aleatória }(\mathrm{n}=29) \text {, com } 25 \% \text { de cada grupo. } \\
\text { Três instrumentos: } 1) \text { entrevista introdutória semi- } \\
\text { estruturada => perfil dos sujeitos; } 2 \text { ) observação } \\
\text { dirigida: registro sobre participação, reflexão, etc.; } \\
\text { 3) entrevista avaliatória: opinião dos idosos sobre } \\
\text { o trabalho dos animadores no alcance dos objetivos }\end{array}$ \\
\hline
\end{tabular}

\begin{tabular}{ll}
\hline Lima (1996) & Avaliações periódicas do conjunto das ações \\
São Paulo / SP & programáticas visando à monitoração sistemática \\
& do trabalho
\end{tabular}

- Resultados têm estimulado a manutenção do grupo como prática assistencial

- Observa-se que os sujeitos, ao se "apropriarem" do grupo, problematizam as questões e com freqüência passam a discutir e "vislumbrar" encaminhamentos e "respostas" para muitos de seus sofrimentos

\begin{tabular}{ll}
\hline Almeida (1998) & Avaliar mudanças qualitativas dos idosos em face \\
Fortaleza / CE & de suas carências iniciais e avaliar o processo de \\
& desenvolvimento do grupo \\
& Base foi o relato de experiência e a reflexão sobre \\
& o trabalho: aponta as necessidades dos idosos em \\
& cada dimensão e as ações trabalhadas no grupo \\
& para responder a elas
\end{tabular}

- Grupo como lugar de compartilhar assuntos importantes da vida, para o lazer e para expressar religiosidade, para resolver problemas de ordem biológica e social através da formação de uma rede de solidariedade

- Satisfação dos idosos com o trabalho (ilustra com um depoimento que realça a afetividade e o bom tratamento recebido no grupo)

\begin{tabular}{ll}
\hline Telarolli (1997) & Questionário auto-aplicável, com perguntas \\
Araraquara / SP & abertas e fechadas, para avaliação geral da \\
& programação educativa. Dos 96 inscritos, 57 \\
& $(59,4 \%)$ responderam ao questionário
\end{tabular}

- Maioria (75,5\%) considerou ótimo o programa, $21 \%$ bom e 3,5\% regular. Oportunidade de aprendizado e também de interações sociais e novas amizades

- Quase 2/3 consideraram cansativas três palestras por turno. Sugerem duas para haver tempo para perguntas. Preferência pelas exposições mais faladas e com menos recursos audiovisuais. Ambigüidade quanto à compreensão dos temas, dada pela possível heterogeneidade cultural do grupo

- Temas preferidos foram os relacionados a problemas de saúde comuns em idosos

- Críticas à ausência do lazer nas atividades oferecidas e à dificuldade dos professores em manter a disciplina nas palestras

- Interesse em voltar a participar, com nova programação 


\section{Limites e recomendações}

Do ponto de vista metodológico, os estudos nacionais não apontam questão ou reflexão para desdobramento em futuras pesquisas. O único aspecto problematizado e avaliado positivamente é a possível implicação da pesquisadora por ter atuado como profissional nos grupos por ela analisados (Teixeira, 2002). De outra parte, reconhecendo a incipiência dos esforços de avaliação, Lima et al. (1996) salientam a necessidade de se desenvolverem instrumentos específicos para avaliar a integração do grupo de idosos no programa realizado na Unidade Básica.

As demais recomendações vão no sentido de apontar caminhos para ampliação e aprimoramento das ações, unanimemente consideradas viáveis e oportunas. No trabalho de Almeida et al. (1998) emerge como preocupação as insuficiências no atendimento às necessidades dos idosos pelo baixo suporte institucional. Para isso sugerem o desenvolvimento de projetos a partir dessas necessidades. Quanto às mudanças sugeridas em relação ao processo educativo foram referidas a necessidade de adequar tempo e recursos pedagógicos às condições de aprendizagem dos idosos, bem como de abrir mais espaços à participação (Telarolli Jr. et al., 1997). Um exemplo de adequação dado pelos participantes é o uso de transparências com letras maiores em virtude da dificuldade visual comum entre idosos (Rodrigues et al., 1999).

Nos estudos internacionais é mais freqüente e variada a problematização acerca dos aspectos metodológicos dos estudos, seus alcances e limites.

Sobre os instrumentos de pesquisa, Kocken et al. (1998) questionam o limite das escalas utilizadas para aferir os itens propostos, sobretudo a auto-eficácia; Ruffing-Rahal (1994) menciona o caráter ainda recente e pouco amadurecido de dois dos quatro instrumentos utilizados, além do tempo curto do follow-up para avaliar efeitos cumulativos das ações; e Brice et al. (1996) avaliam positivamente o instrumento healthy belief index, já usado em outros estudos.

Os limites da amostra são uma questão freqüente dentre outras preocupações com influências indevidas nos resultados. São apontados possíveis vieses quanto ao fato de serem pessoas que voluntariamente quiseram participar (Elder et al., 1995; Ruffing-Rahal, 1994); que são relativamente saudáveis e com bom nível socioeconômico (Brice et al., 1996); e que não re- presentam devidamente a população local (Fox et al., 1997; Ruffing-Rahal, 1994).

Os dois estudos sobre variáveis ligadas à participação não trazem questões metodológicas, talvez pelos seus objetivos relativamente menos complexos. Têm em comum o fato de recomendar inovação nas formas de acesso aos programas para que os serviços preventivos baseados em comunidade alcancem os idosos com maior necessidade. Para Watkins (1993) e Schweitzer (1994), envolver idosos frágeis em promoção da saúde é um desafio, tendo em vista a associação entre não-participação e status de saúde mais pobre.

Atingir as pessoas mais vulneráveis é também uma meta sugerida por Brice et al. (1996) por acreditarem que os resultados das ações poderão ser mais expressivos. Em sentido próximo, Rogers et al. (1992) recomendam que programas de screenings independentes deveriam ser focados nas pessoas que não acessam os médicos da atenção primária.

Sobre as ações educativas há poucas considerações acerca da oportunidade de mudanças. Apenas Kocken et al. (1998) assumem como pequena a programação de quatro sessões para os resultados pretendidos.

As recomendações para futuras pesquisas vão em várias direções, mas todas revelam a preocupação em assegurar bases técnicas e econômicas de sustentabilidade das ações. As necessidades apontadas são:

- pesquisa longitudinal, com grupo controle, para avaliar mudança sustentada de estilos de vida (Parcker et al, 2002);

- Pesquisa continuada para saber se os projetos melhoram o comportamento e o status de saúde a um custo razoável (Schweitzer et al., 1994);

- Tempo do follow-up de 5 a 10 anos para que se avalie o custo-benefício dos programas (Brice et al., 1996);

- Avaliação do impacto de longo prazo da aderência sobre a morbidade e a mortalidade (Fox et al., 1997);

- Amostra maior e aleatória para generalização dos resultados (Ruffing-Rahal, 1994).

Uma recomendação estratégica que merece destaque é o planejamento futuro com previsão da documentação necessária para a avaliação dos efeitos hipotetizados (Parcker et al., 2002; Minkler, 1992). Esta última autora, apesar de avaliar um programa de longa duração (12 anos), reconhece o limite da documentação para aferir efeitos mais generalizados do 
projeto e mudanças no status de saúde. Para ela é reconhecidamente difícil medir certas alterações sutis, razão por que é interessante a combinação de métodos quantitativos e qualitativos. Tal opinião é partilhada por Ruffing-Rahal, (1994) ao afirmar que a triangulação metodológica é um recurso que pode facilitar a especificação das intervenções e dos resultados.

É dessas últimas autoras que partem as únicas reflexões de ordem conceitual-metodológica acerca dos modelos teóricos adotados. De modo profundo e cuidadoso, Minkler (1992) reflete sobre potenciais e limites da metodologia pedagógica de Paulo Freire. Em sua opinião, a aplicação "pura" desta proposta mostrou-se difícil e não realista em alguns aspectos. O diálogo problematizador é útil mas deve ser flexibilizado e suplementado por outras técnicas e métodos de interação social "não orientadas para causa" para responder às necessidades imediatas do grupo. Ruffing-Rahal (1993 e 1994), por sua vez, alerta para a necessidade de se considerar o complexo contexto de saúde e doença dos idosos e ressalta o valor dos temas centrais do modelo de bem-estar ecológico (atividade, afirmação e síntese) para um repertório dos indicadores do processo de grupo. A autora vê aí um caminho para se trilhar indicadores individuais e grupais como medidas de base para avaliar processo e efeitos de grupos de promoção da saúde.

\section{Considerações finais}

Numa síntese do panorama apresentado, observa-se que o campo da promoção da saúde do idoso, na vertente delimitada, é multifacetado quanto às tendências teórico-metodológicas e às estratégias de pesquisa, e apresenta perfis distintos entre a produção nacional e internacional.

A tendência dos programas internacionais é a transmissão de informações, combinada a ações de screening, aconselhamento. É presente, mas não extensiva, a articulação das práticas ao debate contemporâneo sobre promoção da saúde, no que tange a assumir uma perspectiva política e sociocultural ampla. Algumas iniciativas incorporam indicadores de qualidade de vida e bem-estar subjetivo, relacionados a paradigmas recentes de envelhecimento ativo e bem-sucedido.

O limite para ampliação das abordagens e da pesquisa avaliativa, neste contexto, parece refletir a marca positivista que orienta a promoção da saúde nos Estados Unidos, à qual Bucha- nan (2000) faz contundente crítica. Para ele, resumidamente, a pesquisa nesta área é falha pois tenta trabalhar com a mesma lógica da pesquisa experimental utilizada com relativo sucesso na explanação dos processos biológicos. A saúde, apreendida como bem-estar, fica porém na fronteira do mundo natural e social, terreno que desafia possibilidades de predição e controle.

No Brasil confirma-se a pequena tradição de avaliação e de programas de promoção da saúde do idoso. Algumas experiências assemelham-se ao modelo há pouco descrito, porém grande parte demonstra oferecer espaço de maior abertura relacional e tomar a saúde nas suas relações com a realidade social e política. Embora pouco desenvolvida, a avaliação traz dados qualitativos, permitindo, em alguns casos, uma visualização dos processos e da relação dos sujeitos envolvidos.

A perspectiva da Educação Popular em Saúde é presente como aporte teórico das ações educativas com idosos, sobretudo no contexto nacional, e há semelhanças desta com outras abordagens ou pressupostos, ainda que não nomeada pelos autores. Chama a atenção a apropriação consistente da metodologia de Paulo Freire por uma autora americana, ainda que não representativa da tendência hegemônica em promoção da saúde naquele país.

A contribuição desta vertente ao desenvolvimento dos programas alinha-se às preocupações com riscos ideológicos da promoção da saúde quando esta é reduzida na prática a uma questão de escolhas individuais (Czeresnia, 2003). A abordagem sobre comportamentos e práticas saudáveis deve incluir a reflexão sobre a produção social da saúde-doença e reconhecer o contexto pessoal, cultural e político como dimensões relevantes na dinâmica das ações educativas e na apreensão de resultados das intervenções. Pela complexidade aí envolvida, parâmetros como ética, diálogo, amorosidade e valorização do outro e de seus saberes devem ser especialmente considerados na relação entre profissionais de saúde e idosos.

De modo geral, e baseado na majoritária apreciação positiva dos idosos acerca das ações, os programas podem ser vistos como aberturas interessantes, com grau de alcance variado, ao investimento em saúde e bem-estar do idoso para além da lógica usual de assistência à doença. Seus méritos e limites devem ser apreciados no processo de desenvolvimento da promoção da saúde do idoso e das estratégias de avaliação de programas nessa área no contexto brasileiro. 


\section{Colaboradores}

A Mônica trabalhou na pesquisa bibliográfica, na sistematização dos estudos de avaliação e na redação; H Zulmira, na concepção, na orientação da pesquisa bibliográfica e na revisão do texto; e V Victor, na orientação e revisão do texto.

\section{Referências bibliográficas}

Almeida MI, Silva MJ \& Araújo MFM 1998. Grupo Vida: adaptação bem-sucedida e envelhecimento feliz. Revista da Associação de Saúde Pública do Piauí 1(2): 155-162.

Assis M 2004. Promoção da Saúde e Envelhecimento: avaliação de uma experiência no ambulatório do Núcleo de Atenção ao Idoso da UnATI / UERJ. Tese de doutorado. Escola Nacional de Saúde Pública, Rio de Janeiro.

Brice GC, Gorey KM \& Angelino RMHS 1996. The STAYWELL Program - maximizing elders'capacity for independent living through health promotion and disease prevention activities. A quasi-experimental evaluation of its efficacy. Research on Aging 18(2):202-215.

Buchanan DR 2000. An ethic for health promotion. Oxford University Press, Oxford (NY).

Buss PM 2003. Uma introdução ao conceito de promoção da saúde, pp. 15-38. In C Czeresnia \& CM Freitas (orgs.). Promoção da Saúde. Conceitos, reflexões, tendências. Fiocruz, Rio de Janeiro.

Diogo MJDE, Ceolim MF \& Cintra FA 2000. Implantação do Grupo de Atenção à Saúde do Idoso (GRASI) no Hospital de Clínicas da Universidade Estadual de Campinas (SP): Relato de Experiência. Revista Latino-americana de Enfermagem 8(5):85-90.

Elder JP et al. 1995. Longitudinal effects of preventive services on health behaviors among an elderly cohort. American Journal of Preventive Medicine 11(6):354-359.

Ferrari MAC 1999. O envelhecer no Brasil. O Mundo da Saúde. São Paulo, 23(4), 197:203.

Fletcher A, Breeze E \& Walters R 1999. Health promotion for the older people: what are the opportunities? Promotion \& Education 6(4):4-7.

Frutuoso D 1999. A Terceira Idade na universidade. Relacionamento entre gerações no terceiro milênio. Ágora da Ilha, Rio de Janeiro.

Fox PJ, Breuer W \& Wright JA 1997. Effects of a health promotion program on sustaining health behavior in olders adults. American Journal of Preventive Medicine 13(4):257-264.

Keller C \& Fleury J 2000. Health promotion for the elderly. Sage, Thousand Oaks.

Kocken PL \& Voorham AJJ 1998. Effects of a peer-led senior health education program. Patient Educacion and Counseling 34:15-23.

Lima AMM et al., 1996. Saúde no envelhecimento, pp. 109-132. In LB Schraiber (org.). Saúde do adulto. Programas e ações na unidade básica. Hucitec, São Paulo.

Lopes MJM, Silveira DT \& Ferreira SRS 1999. Educação em saúde nas doenças crônico-degenerativas e a promoção da qualidade de vida: relato de experiência. Estudos Interdisciplinares sobre Envelhecimento 2:121-130.

Minkler M 1992. Community organizing among the el- derly poor in the United States: a case study. International Journal of Health Services 22(2):303-316.

Neri AL \& Cachioni M 1999. Velhice bem-sucedida e educação, pp. 113-140. In AL Neri \& GG Debert (orgs.). Velhice e sociedade. Papirus, São Paulo.

Nicola IP 1999. Formação de recursos humanos para uma ação educativa gerontológica. Gerontologia 7(4): 178-191.

Parker MW et al., 2002. A multidisciplinary model of health promotion incorporating spirituality into a successful aging intervention with african-american and white elderly groups. The Gerontologist 42(3): 406-415.

Pawson R 2002. Evidence-based policy: the promise of "realist synthesis". Evaluation 8(3):340-358.

Portella MR 1999. Cuidar para um envelhecer saudável. Revista Brasileira de Enfermagem 52(3):355-364.

Rodrigues RAP et al. 1999. Avaliação de aprendizagem de idosos: viver com saúde na velhice. Gerontologia 7(1):17-22.

Rogers J, Grower R \& Supino P 1992. Participant evaluation and cost of a community-based health promotion program for elders. Public Health Reports 107(4): 417-426.

Rootman I et al. 2001. A framework for health promotion evaluation, pp. 7-38. In I Rootman et al. (eds.). Evaluation in health promotion. Principles and perspectives. WHO Regional publications. European Series. Dinamarca.

Ruffing-Rahal MA 1993. An ecological of group well-being: implications for health promotion with older women. Health Care for Women International 14:447456.

Ruffing-Rahal MA 1994. Evaluation of group health promotion with community-dwelling older women. Public Health Nursing 11(1):38-48.

Schweitzer SO et al. 1994. Health promotion and disease prevention for older adults: opportunity for change or preaching to the converted? American Journal of Preventive Medicine 10(4):223-229.

Teixeira MB 2002. Empoderamento de idosos em grupo voltado à promoção da saúde. Dissertação de mestrado. Escola Nacional de Saúde Púbica, Fiocruz, Rio de Janeiro.

Telarolli Jr., Machado JCMS \& Carvalho F 1997. Educação em saúde na Terceira Idade. Avaliação de um programa de extensão universitária. Gerontologia 5(2):55-65.

Valla VV 2000. Educação popular e saúde diante das formas alternativas de se lidar com a saúde. Revista de Atenção Primária à Saúde Nates/UfJF 3(5):46-53.

Vasconcelos EM 2001. Redefinindo as práticas de saúde a partir da Educação Popular nos Serviços de Saúde, pp. 11-20. In EM Vasconcelos (org.). A saúde nas palavras e nos gestos. Reflexões da Rede de Educação Popular e Saúde. Hucitec, São Paulo.

Watkins A \& Kligman EW 1993. Attendance patterns of olders adults in a health promotion programa. Public Health Reports 108(1):86-90.

WHO/NMH/NPH 2002. Active ageing: a policy framework. Disponível em $<$ http://www.who.int/hpr/ageing $>$

Artigo apresentado em 26/4/2004

Aprovado em 4/6/2004

Versão final apresentada em 24/6/2004 